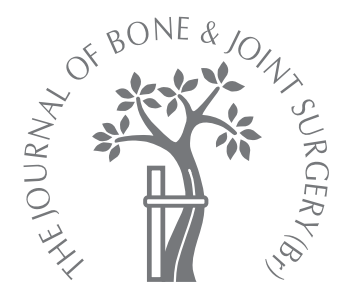

\title{
Treatment of osteonecrosis of the femoral head with hBMP-2-gene-modified tissue- engineered bone in goats
}

\author{
T. T. Tang, \\ B. Lu, \\ B. Yue, \\ X. H. Xie, \\ Y. Z. Xie, \\ K. R. Dai, \\ J. X. Lu, \\ J. R. Lou
}

From Shanghai

Ninth People's

Hospital, Shanghai,

Republic of China

\begin{abstract}
T. T. Tang, MD, PhD, Professor
B. Lu, MD, Orthopaedic Surgeon

B. Yue, MD, Orthopaedic Surgeon

X. H. Xie, MD, Orthopaedic Surgeon

Y. Z. Xie, MD, PhD,

Orthopaedic Surgeon

K. R. Dai, MD, Professor

Department of Orthopaedic

Surgery

Shanghai Ninth People's

Hospital, Shanghai Jiao Tong

University School of Medicine, 639 Zhizaoju Road, Shanghai
\end{abstract} 200011, Republic of China.

J. X. Lu, MD, PhD, Professor Laboratoire de Recherche sur

les Biomatériaux et les

Biotechnologies

Université du Littoral Côte

d'Opale, 62608 Berck sur Mer

France.

J. R. Lou, MD, Professor

Shanghai Institute of Biological Products, 1262 Yananxi Road,

Shanghai 200052, People's

Republic of China.

Correspondence should be sent to Professor T. T. Tang, e-mail: tingtingtang@hotmail.com

(C)2007 British Editorial Society of Bone and Joint Surgery doi:10.1302/0301-620X.89B1 $18350 \$ 2.00$

Bone Joint Surg $[\mathrm{Br}]$

2007;89-B:127-32.
Received 30 June 200

Accepted 16 August 2006

The efficacy of $\beta$-tricalcium phosphate ( $\beta$-TCP) loaded with bone morphogenetic protein-2 (BMP-2)-gene-modified bone-marrow mesenchymal stem cells (BMSCs) was evaluated for the repair of experimentally-induced osteonecrosis of the femoral head in goats.

Bilateral early-stage osteonecrosis was induced in adult goats three weeks after ligation of the lateral and medial circumflex arteries and delivery of liquid nitrogen into the femoral head. After core decompression, porous $\beta$-TCP loaded with BMP-2 gene- or $\beta$-galactosidase (gal)-gene-transduced BMSCs was implanted into the left and right femoral heads,

respectively. At 16 weeks after implantation, there was collapse of the femoral head in the untreated group but not in the BMP-2 or $\beta$-gal groups. The femoral heads in the BMP-2 group had a normal density and surface, while those in the $\beta$-gal group presented with a low density and an irregular surface. Histologically, new bone and fibrous tissue were formed in the macropores of the $\beta$-TCP. Sixteen weeks after implantation, lamellar bone had formed in the BMP-2 group, but there were some empty cavities and residual fibrous tissue in the $\beta$-gal group. The new bone volume in the BMP-2 group was significantly higher than that in the $\beta$-gal group. The maximum compressive strength and Young's modulus of the repaired tissue in the BMP-2 group were similar to those of normal bone and significantly higher than those in the $\beta$-gal group.

Our findings indicate that porous $\beta$-TCP loaded with BMP-2-gene-transduced BMSCs are capable of repairing early-stage, experimentally-induced osteonecrosis of the femoral head and of restoring its mechanical function.

Osteonecrosis of the femoral head is a common disorder with a complex aetiology. ${ }^{1,2}$ The limited capacity for repair in the dead zone of the subchondral bone leads to collapse of the articular surface, with ensuing degeneration of the hip. Protected weight-bearing, core decompression, osteotomy, and vascularised or nonvascularised bone grafting have been used to treat osteonecrosis before the collapse of the femoral head, but the results of these procedures are far from perfect. ${ }^{3-5}$ The only effective treatment for the collapsed femoral head is total hip replacement, although reports show a higher frequency of failure in the long term..$^{6-7}$ Recently, enhancement of bone repair in the necrotic zone by bone-marrow-derived mesenchymal stem cells (BMSCs) has been highlighted for the treatment of osteonecrosis before collapse of the head. ${ }^{8}$ However, both the number and the activity of the BMSCs decrease in patients with necrosis of the femoral head and there is also a decrease in the proliferative capacity of the osteoblastic cells in the proximal femur. ${ }^{9,10}$ Some studies have also shown that autologous bone marrow containing a small number of BMSCs may be used to treat necrosis ${ }^{11,12}$ and that a limited number of BMSCs could be amplified in vitro to enhance the therapeutic efficacy.

Differentiation of BMSCs requires induction by growth factors. Bone morphogenetic proteins (BMPs) including BMP-2, -4 , and -7 are a group of multifactorial growth factors belonging to the transforming growth factor- $\beta$ superfamily and have been shown to promote and to induce bone formation and to accelerate the healing of bone defects. ${ }^{13}$ This has been shown in recent studies in which BMPs have played a significant role in the treatment of osteonecrosis. ${ }^{14-16}$ However, the short half-life and the high concentration needed in vivo may limit their applications. Gene-transfer techniques provide an effective means of transducing and expressing BMPs in BMSCs. The implantation of different scaffolds loaded with BMP-2-genetransferred BMSCs is capable of repair in segmental bone defects. ${ }^{17-19}$ Therefore, our hypothesis was that porous tricalcium 
Table I. Distribution of goats after the implantation of the tissue-engineered bone

\begin{tabular}{|c|c|c|c|c|c|c|c|c|c|}
\hline \multirow[b]{2}{*}{ Interval (wks) } & \multirow{2}{*}{$\begin{array}{l}\text { Establish the } \\
\text { necrosis } \\
0\end{array}$} & \multicolumn{3}{|c|}{ In vivo $\mathrm{BMP}-2^{*}$ concentration } & \multicolumn{3}{|c|}{ Histology } & \multirow{2}{*}{$\begin{array}{l}\text { Biomechanical } \\
\text { test } \\
16\end{array}$} & \multirow[t]{2}{*}{ Total } \\
\hline & & 1 & 2 & 3 & 6 & 10 & 16 & & \\
\hline Untreated group $^{\dagger}$ & 3 & - & - & - & - & - & 3 & & 6 \\
\hline$\beta$-gal group ${ }^{\ddagger}$ and BMP-2 group ${ }^{\S}$ & - & 3 & 3 & 3 & 2 & 2 & 5 & 5 & 23 \\
\hline
\end{tabular}

*BMP-2, bone morphogenetic protein-2

$\dagger$ bilateral femoral heads

$\neq \beta$-gal, $\beta$-galactosidase; left femoral heads

$\S$ right femoral heads

\begin{tabular}{llcl}
\multicolumn{4}{l}{ Table II. Mean (SD) in vivo bone morphogenetic protein-2 (BMP-2) concentration after implantation (pg/mg) } \\
\hline Interval (wks) & $\mathbf{1}(\mathbf{n}=\mathbf{3})$ & $\mathbf{2}(\mathbf{n}=\mathbf{3})$ & $\mathbf{3}$ (n = 3) \\
\hline$\beta$-gal ${ }^{*}$ group & $116.21(22.36)$ & $98.45(17.13)$ & $126.58(19.67)$ \\
BMP-2 group & $807.26(67.87)$ & $854.22(94.98)$ & $685.34(143.56)$ \\
\hline
\end{tabular}

phosphate (TCP), loaded with BMP-2-gene-transferred BMSCs, could accelerate repair in the necrotic zone of the subchondral bone and prevent collapse of the femoral head with osteonecrosis in a goat model.

\section{Materials and Methods}

Scaffolds. Cylindrical scaffolds were made of $75 \% \pm 10 \%$ SD macroporous, $\beta$-TCP (Biocétis, Berck sur Mer, France). They were $10 \mathrm{~mm}$ long and $6 \mathrm{~mm}$ in diameter. The mean pore size was $400 \mu \mathrm{m}$ in diameter. This ceramic has been shown to be osteoconductive. ${ }^{20}$

Culture of BMSCs and BMP-2 gene transfer. BMSCs were derived from aspirates of $4 \mathrm{ml}$ from an iliac wing of each goat. The bone marrow was plated in flasks with $\alpha$-minimal Eagle's medium (HyClone, Logan, Utah) supplemented with $10 \%$ fetal bovine serum, $100 \mathrm{U} / \mathrm{ml}$ of penicillin, and $100 \mu \mathrm{g} / \mathrm{ml}$ of steptomycin. The adherent cells were expanded. Recombinant adenovirus containing human BMP-2-gene (Adv-hBMP-2) and recombinant adenovirus containing $\beta$-galactosidase (Adv- $\beta$ gal) were constructed as has been reported previously. ${ }^{21}$ Viral stocks were amplified and titred in 293 cells. The BMSCs were transduced by adenovirus overnight with a multiplicity of infection of $200 .{ }^{17}$

Preparation of the tissue-engineered bone. Gene-modified BMSCs were trypsinised and the cell suspension was prepared at a concentration of $5 \times 10^{7}$ cells $/ \mathrm{ml}$. Approximately $1 \times 10^{7}$ cells were loaded on to a $\beta$-TCP cylinder. The cell composites were subsequently incubated at $37^{\circ} \mathrm{C}$ for four hours before implantation.

Establishment of osteonecrosis of the femoral head and implantation. We obtained 29 mature goats weighing between $15 \mathrm{~kg}$ and $20 \mathrm{~kg}$ from a licenced vendor (Shanghai Agricultural College, Shanghai, People's Republic of China). They were cared for according to the guidelines for the care and the use of laboratory animals delivered by the Shanghai Science and Technology Committee. ${ }^{22}$ Bilateral osteonecrosis of the femoral head was established accord- ing to the method described by Conzemius et al. ${ }^{23}$ In brief, the goats were anaesthetised and a skin incision $10 \mathrm{~cm}$ long was made to expose the hip. The lateral and medial femoral circumflex arteries were identified and ligated. A tunnel $6 \mathrm{~mm}$ long, opening at the juncture of the femoral head and neck was created by a serrated-tip drill guide $3.5 \mathrm{~mm}$ in diameter. After drilling, the bone in the tunnel was removed. Nitrogen liquid was slowly dropped into the tunnel and warm saline was used to re-warm the surgical field. The freeze-thaw cycle was repeated several times. The surrounding soft tissue was protected by absorbant gauze. The same surgical procedure was performed on both the hips. Three weeks later, three goats were killed and the six femoral heads harvested to observe the histological changes of early necrosis (Table I). The remaining goats were subdivided and treated. A core decompression of the femoral head was carried out in 23. The core tract, $6 \mathrm{~mm}$ in diameter, was filled with the tissue-engineered bone. The BMP-2gene-modified tissue-engineered bones were implanted in the right femoral heads (BMP-2 group) and the $\beta$-gal-genemodified tissue-engineered bones in the left ( $\beta$-gal group). The other three goats were used as the untreated control group.

Quantitative enzyme-linked immunosorbant assay (ELISA) determination of local BMP-2 in vivo concentrations. Three goats from the BMP- 2 group and the $\beta$-gal group were killed at 1,2 , and 3 weeks after implantation. The implanted $\beta$-TCPs containing the repairing tissue were harvested. Proteins were extracted according to the method described by Noshi et al. ${ }^{24}$ The samples were ground into particles in liquid nitrogen washed with $10 \mathrm{mM}$ sodium azide (NaN3) and defatted with chloroform/methanol (1:1). They were then decalcified in $0.6 \mathrm{M}$ hydrochloric acid $(\mathrm{HCl})$ and extracted at a $\mathrm{pH}$ of 7.4 with $3 \mathrm{ml}$ of icecold buffer, which contained $4 \mathrm{M}$ guanidine- $\mathrm{HCl}, 10 \mathrm{mM}$ $\mathrm{CaC1}_{2}, 50 \mathrm{mM}$ Tris, and protease inhibitors (Protease Inhibitor Cocktails, Sigma-Aldrich Corporation, St Louis, Missouri). The extraction was performed at $4^{\circ} \mathrm{C}$ for 16 


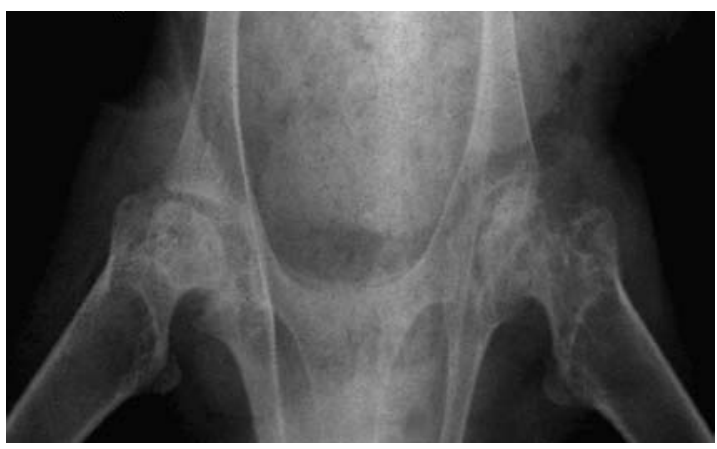

Fig. 1a

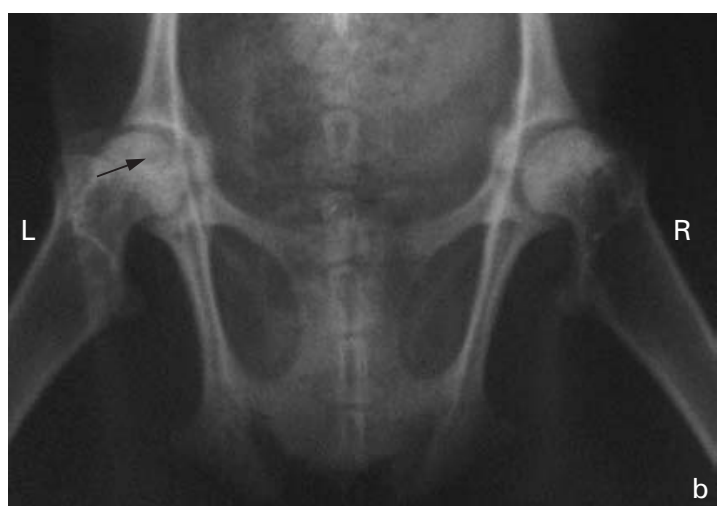

Fig. 1b

Radiographs at 16 weeks after implantation. Figure $1 \mathrm{a}-$ In the untreated group, both femoral heads have collapsed with an abnormal contour and increased density. Figure $1 b-(R)$ in the bone morphogenetic protein-2 group, the femoral head has not collapsed. The density and the shape are nearly normal, (L) in the $\beta$-galactosidase) group, the femoral head has not collapsed, but there is a cystic low-density zone (arrow) and an irregular surface of the head.

hours by shaking. The extracts were dialysed against distilled water, centrifuged at $40000 \times g$ for 30 minutes at $4^{\circ} \mathrm{C}$, and lyophilised. The lyophilised precipitate was dissolved in $0.15 \mathrm{M} \mathrm{NaCl}, 50 \mathrm{mM}$ Tris- $\mathrm{HCl}$, and $6 \mathrm{M}$ urea at $\mathrm{pH} 7.4$, and applied to a heparin-sepharose CL-6B column (Pharmacia, Pfizer Corp., New York). The applied sample was eluted with $0.7 \mathrm{M} \mathrm{NaC1}, 50 \mathrm{mM}$ Tris- $\mathrm{HCl}$, and $6 \mathrm{M}$ urea at a $\mathrm{pH}$ of 7.4. BMP-containing fractions were dialysed against distilled water and lyophilised. The partially purified BMP was extracted at least three times to maintain constant quality. The final sample was dissolved in $2 \mathrm{M}$ guanidine- $\mathrm{HCl}$ and stored at $4^{\circ} \mathrm{C}$. The concentration of BMP-2 was determined by a Quantikine BMP-2 ELISA kit (R\&D Systems Inc., Ottawa, Canada) according to the protocol recommended by the manufacturer. The BMP-2 concentration was expressed as the BMP- 2 content in $1 \mathrm{mg}$ of $\beta$-TCP sample.

Radiological analysis. Anteroposterior radiographs were taken in each group immediately after, and then at 16 weeks following, implantation. Changes in the femoral head were observed and noted.
Histological analysis. A total of 12 goats were killed at six ( 2 goats), ten (2), and 16 weeks ( $8 ; 5$ treated, 3 untreated) after implantation (Table I). Histological analysis was performed to observe the osteonecrotic changes in the femoral heads. The specimens were fixed in $10 \%$ buffered neutral formalin and decalcified in $0.25 \mathrm{M}$ ethylenediaminetetraacetic acid (EDTA). They were then cut longitudinally and embedded in paraffin. The sections from the centre of the femoral head were sliced and stained with haematoxylin and eosin.

The quantitative study was carried out on sections from the specimens harvested at the 16 th week after implantation. The new bone volume was measured by semi-automatic analysis software (Image-Pro Plus 5.0, Media Cybernetics Inc., Silver Spring, Maryland). The percentage of new bone/ total area of tissue was calculated.

Biomechanical analysis. The femoral heads of five goats harvested at the 16th week were placed in an ice-bath of saline solution before the test. The implantation area in the femoral head was shaped into a size of $4 \times 4 \times 6 \mathrm{~mm}^{3}$. The tissue from the normal femoral heads was also tested. Compressive tests were performed with a material mechanical testing machine (SHIMADZU AG-A 2000, Kyoto, Japan). The compressive loading speed was approximately $2 \mathrm{~mm} / \mathrm{min}$. The maximum compressive strength and Young's elastic modulus $^{25}$ were also determined.

Statistical analysis. The new bone volume in the BMP-2 group and the $\beta$-gal group was compared by Student's $t$-test. For each variable in the biomechanical test, one-way analysis of variance (ANOVA) was used to compare the means $( \pm$ SD) of each group. A p-value $\leq 0.05$ was considered to be statistically significant. Statistical analysis to compare the local in vivo BMP-2 concentrations between the BMP-2 group and the $\beta$-gal groups was not undertaken because the sample size was too small.

\section{Results}

In vivo $\mathrm{BMP}-2$ concentration. $\mathrm{BMP}-2$ proteins were detectable in the cell/TCP composites harvested from the femoral heads in both groups, one, two, and three weeks after implantation. The mean concentration of BMP-2 at each time point was higher in the BMP-2 group that in the $\beta$-gal group (Table II). This result suggested that the implanted BMP-2-gene-transferred cells were able to secrete more BMP-2 proteins in the femoral head for at least three weeks, while the native production of BMP-2 proteins in the femoral head was limited.

Radiological analysis. In the control group, the classical signs of osteonecrosis, including collapse, abnormal contour, and increased density of the femoral head, were identified on radiographs 16 weeks after the operation (Fig. 1a). There was no evidence of collapse of the femoral head in either the BMP-2 group or the $\beta$-gal group. The density and surface of the femoral head were normal in the BMP-2 group, while an inhomogeneous density and an irregular surface were identified in the $\beta$-gal group (Fig. 1b). 


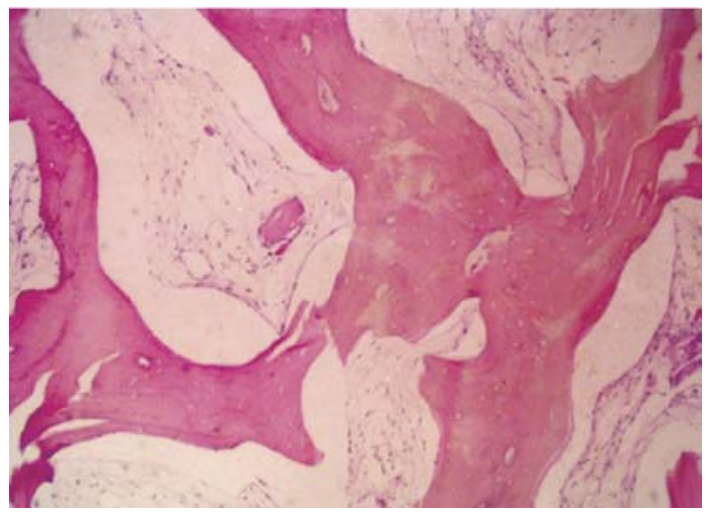

Fig. 2a

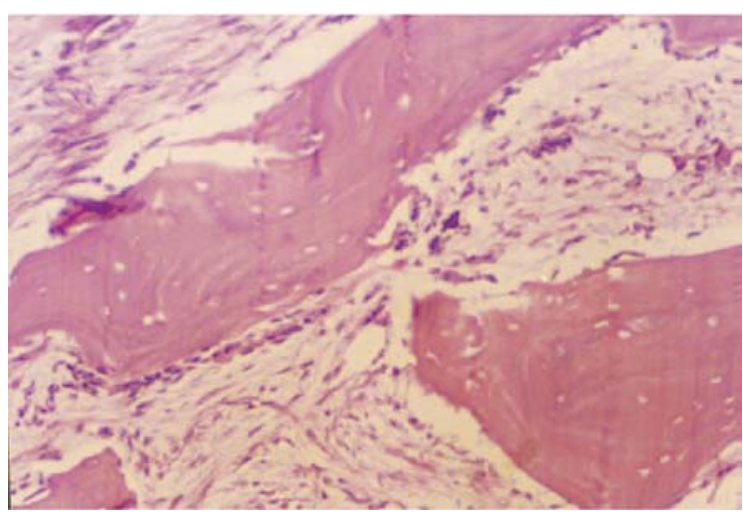

Fig. $2 b$

Photomicrographs three weeks after induction of osteonecrosis, showing a) normal marrow was replaced with fibrotic marrow and numerous osteocyte-filled lacunae have become empty (haematoxylin and eosin $x 40$ ) and b) at 16 weeks, massive trabeculae have been absorbed and the marrow space filled with dense granulation tissue (haematoxylin and eosin $x 100$ ).

Table III. Comparisons of mean (SD) new bone volume between the bone morphogenetic protein-2 (BMP-2) and the $\beta$-galactosidase ( $\beta$-gal) groups $(n=5)$ after 16 weeks

\begin{tabular}{ll}
\hline Group & New bone volume \\
\hline$\beta$-gal & $12.87(2.35)$ \\
BMP-2 & $57.58(7.42)$ \\
\hline
\end{tabular}

Histological analysis. In the six femoral heads from the three goats three weeks after induction of osteonecrosis, normal marrow had been replaced by fibrotic marrow, and a large number of osteocyte-filled lacunae by empty lacunae (Fig. 2a). This suggested that early-stage osteonecrosis of the femoral head had been successfully established. At 16 weeks, the late stage of osteonecrosis was observed in the control group with massive trabecular resorption and dense granulation tissue in the marrow space (Fig. 2b).

New bone and fibrous tissue in the macropores of the $\beta$-TCP scaffolds, and degradation of the scaffolds were identified in both the BMP- 2 and the $\beta$-gal groups, six and ten weeks after implantation. New bone was more evident in the BMP-2 group than in the $\beta$-gal group (Fig. 3); by 16 weeks most of the scaffolds had degraded and had been replaced by new lamellar bone in the BMP-2 group, while fibrous tissue was found in most of the scaffolds in the $\beta$-gal group (Fig. 3). Histomorphometric analysis revealed that the new bone volume was significantly higher in the BMP-2 group than in the $\beta$-gal group ( $\mathrm{p}=0.003$ ) (Table III).

Biomechanical analysis. The mean maximum compressive strength and Young's modulus were significantly higher $(\mathrm{p}<0.05)$ in the BMP-2 group than in the $\beta$-gal group 16 weeks after implantation (Table IV). The difference between the BMP-2 group and the normal tissue was not statistically significant.

\section{Discussion}

Establishment of an animal model for osteonecrosis of the femoral head is important in the evaluation of the effects of various treatments for osteonecrosis. A considerable amount of work has been done to establish this model, ${ }^{24,26}$ each version demonstrating various aspects of the early histopathological features of the disorder. However, previous models have failed to progress to the endstage of collapse. Recently, Conzemius et $\mathrm{al}^{23}$ successfully established a new osteonecrosis Emu model by ligation of the vascular supply to the femoral head and delivery of liquid nitrogen. The pathological changes in this model are close to both the early- and late-stage pathological changes in man. In this model, deep freezing of the bone by delivery of liquid nitrogen caused necrosis around the core tract in the femoral head. ${ }^{23}$ Ligation of the medial and lateral femoral circumflex arteries interrupted the main blood supply to the head, and may have further hindered repair of the necrotic bone. ${ }^{23}$

We used the same method to establish osteonecrosis in our study. In our model, the early-stage changes of osteonecrosis after three weeks and of end-stage collapse at 16 weeks were revealed grossly, radiologically, and histologically. Unlike the study of Conzemius et $\mathrm{al}^{23}$ our intervention was performed three weeks after induction, when earlystage osteonecrosis had already been established. After core decompression, we implanted the $\beta$-TCP scaffolds/genetransferred BMSCs. In orthopaedic practice, core decompression is usually combined with different bone grafts to treat osteonecrosis of the femoral head. ${ }^{27,28}$ We supplemented core decompression with $\beta$-TCP scaffolds/genetransferred BMSCs to accelerate bone repair. We found formation of new bone in the macropores of the $\beta$-TCP scaffolds and degradation of the materials in both the BMP-2 and the $\beta$-gal groups. The new bone volume was higher in the BMP-2 group than in the $\beta$-gal group, suggesting that BMP-2-gene-modified tissue-engineered bone could enhance osteogenesis of the stem cells.

Successful repair of bone defects with implantation of hBMP-2-gene-transferred BMSCs has already been 


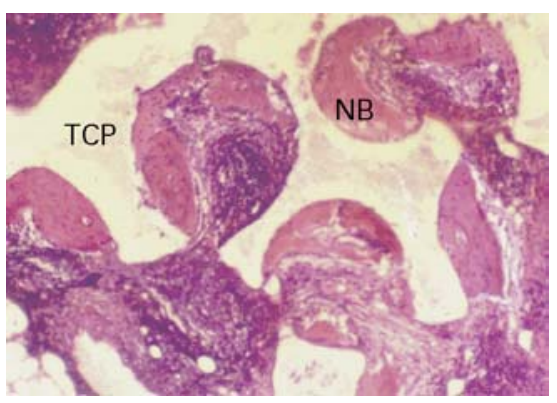

Fig. 3a

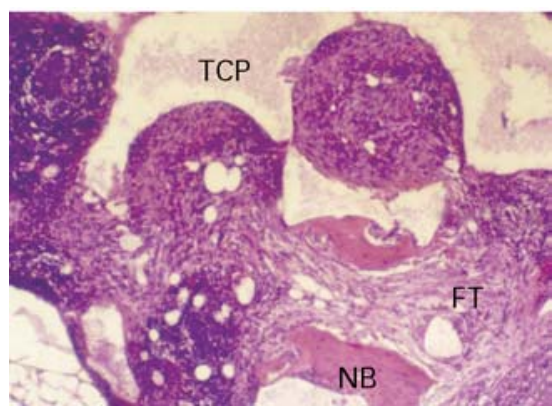

Fig. 3d

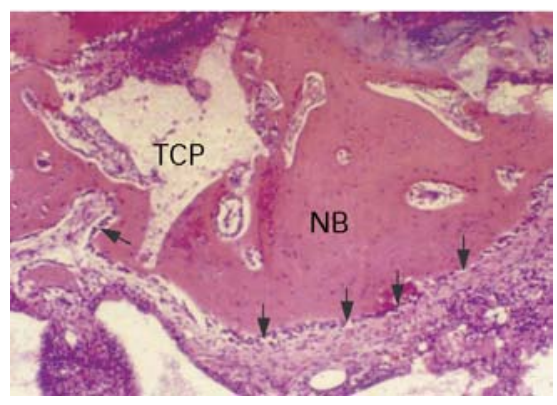

Fig. 3b

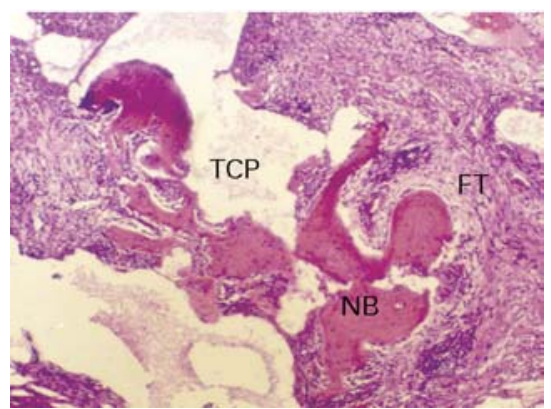

Fig. 3e

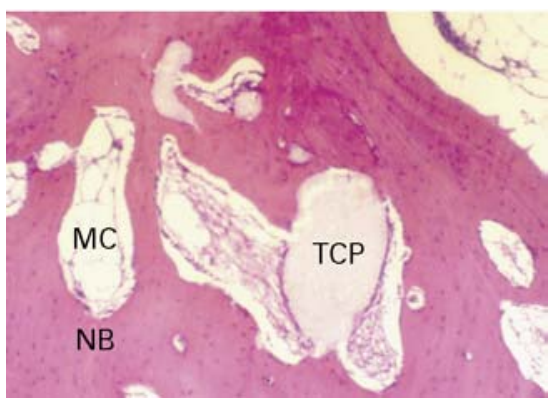

Fig. 3c

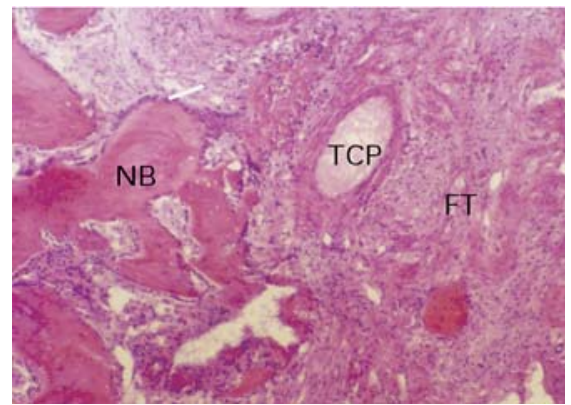

Fig. $3 f$

Photomicrographs showing development of new bone and fibroblasts a) in the bone morphogenetic protein-2 (BMP-2) group, six weeks after implan tation of the cell/scaffold composites, there was formation of new bone (NB) in the macropores of the $\beta$-tricalcium phosphate (TCP), b) at the 10th week the new bone was well connected and the osteoblasts were lined on the new bone surface (arrows) c) at the 16th week, the mature lamellar bone anc the medullary cavity (MC) had formed. In the $\beta$-galactosidase ( $\beta$-gal) group, the macropores of the $\beta$-TCP were mainly filled with fibrous tissue (FT) d) at the 6th, e) 10th and f) 16th weeks (haematoxylin and eosin $x$ 40).

Table IV. The mean (SD) maximum compressive strength and Young's modulus after 16 weeks

\begin{tabular}{llll}
\hline Group $^{*}$ & Number & Maximum compressive strength (MPa) & Young's modulus \\
\hline Normal & 6 & $41.76(5.68)$ & $96.65(8.52)$ \\
$\beta$-gal & 5 & $21.78(3.37)$ & $46.36(4.76)$ \\
BMP-2 & 5 & $38.35(4.16)$ & $86.85(7.28)$ \\
\hline
\end{tabular}

* $\beta$-gal, $\beta$-galactosidase; BMP-2, bone morphogenetic protein-2

reported. ${ }^{29}$ We have further demonstrated the effectiveness of BMP-2 gene therapy in a pathological condition. Although recent reports have shown the efficacy of recombinant hBMP-2 or partially purified human BMPs, ${ }^{14-16}$ some researchers have pointed out that when BMPs are secreted naturally by the cells, only tiny (ng) quantities of the proteins per gram of bone matrix are enough to trigger the cascade of bone repair. However, larger $(\mu \mathrm{g})$ quantities of BMP per gram of matrix material were needed to produce the same effect. ${ }^{30}$ In our study, the in vivo concentration of BMP-2 was 685 to $807 \mathrm{pg} / \mathrm{mg}$ of materials at one, two or three weeks after implantation of the BMP-2 genetransferred cell composites.

The limited repair of necrotic bone along with immature new bone could have contributed to the collapse of the femoral head. In our study, collapse of the femoral head occurred in the control group, but not in the BMP-2 or the $\beta$-gal groups 16 weeks after implantation, perhaps because of support by the implanted $\beta$-TCP scaffold. Furthermore, we have demonstrated that the mechanical properties of the regenerated tissue in the BMP-2 group were significantly better than those of the $\beta$-gal group. Microscopic examination also revealed that new bone in the BMP-2 group had remodelled into lamellar bone, which provided good mechanical strength against compression. Although the weight-bearing properties of goat bone differ from those of human bone, it is reasonable to suggest that BMP-2 gene therapy could effectively restore the mechanical function of the reparative tissue to prevent the femoral head from collapsing in patients with osteonecrosis.

We wish to thank the technical assistance of Mr C.-F. Yu. The study was funded by the Shanghai Science and Technology Development Grant 01JC14028.

No benefits in any form have been received or will be received from a commercial party related directly or indirectly to the subject of this article. 


\section{References}

1. Aaron RK. Osteonecrosis: etiology. pathophysiology, and diagnosis. In: Callaghan JJ, Rosenberg AG, Rubash HE, eds. The adult hip. Vol. 1. Philadelphia: Raven Press, 1998:451.

2. Kiaer T, Pedersen NW, Kristensen KD, Starklint H. Intra-osseous pressure and oxygen tension in avascular necrosis and osteoarthritis of the hip. J Bone Joint Surg $[\mathrm{Br}]$ 1990;72-B:1023-30.

3. Lieberman JR, Berry DJ, Mont MA, et al. Osteonecrosis of the hip: management in the 21st century. Instr Course Lect 2003;52:337-55.

4. Mont MA, Jones LC, Einhorn TA, Hungerford US, Reddi A. Osteonecrosis of the femoral head: potential treatment with growth and differentiation factors. Clin Orthop 1998;355 (Suppl):314-35.

5. Yoon TR, Song EK, Rowe SM, Park CH. Failure after core decompression in osteonecrosis of the femoral head. Int Orthop 2001;24:316-18.

6. Garino JP, Steinberg ME. Total hip arthroplasty in patients with avascular necrosis of the femoral head: a 2- to 10-year follow-up. Clin Orthop 1997;334:108-15.

7. Katz RL, Bourne RB, Rorabeck CH, McGee H. Total hip arthroplasty in patients with avascular necrosis of the hip: follow-up observations on cementless and cemented operations. Clin Orthop 1992;281:145-51.

8. Sun W, Li Z, Shi Z, et al. Effect of non-hydroxyapatite collagen bone and marrow mesenchymal stem cell on treatment of rabbit osteonecrosis of the femoral head defect. Chinese J Reparative Reconstruc Surg 2005;19:203-6.

9. Gangji V, Hauzeur JP, Schoutens A, et al. Abnormalities in the replicative capacity of osteoblastic cells in the proximal femur of patients with osteonecrosis of the femora head. J Rheumato/ 2003;30:348-51.

10. Hernigou P, Beaujean F, Lambotte JC. Decrease in the mesenchymal stem-cell pool in the proximal femur in corticosteroid-induced osteonecrosis. J Bone Joint Surg $[\mathrm{Br}]$ 1999;81-B:349-55.

11. Gangji V, Hauzeur JP, Matos C, et al. Treatment of osteonecrosis of the femoral head with implantation of autologous bone-marrow cells: a pilot study. J Bone Joint Surg [Am] 2004;86-A:1153-60.

12. Hernigou P, Beaujean F. Treatment of osteonecrosis with autologous bone marrow grafting. Clin Orthop 2002;405:14-23.

13. Reddi AH. Bone morphogenetic proteins: from basic science to clinical applications. $J$ Bone Joint Surg [Am]2001;83-A (Suppl):1-6.

14. Lieberman JR, Conduah A, Urist MR. Treatment of osteonecrosis of the femoral head with core decompression and human morphogenetic protein. Clin Orthop 2004;429:13945.

15. Mont MA, Jones LC, Elias JJ, et al. Strut-autografting with and without osteogenic protein-1: a preliminary study of a canine femoral head defect model. J Bone Joint Surg [Am]2001:83-A:1013-22
16. Simank HG, Manggold J, Sebald W, et al. Bone morphogenetic protein-2 and growth and differentiation factor-5 enhance the healing of necrotic bone in a sheep model. Growth Factors 2001;19:247-57.

17. Dai KR, Xu XL, Tang TT, et al. Repairing of goat tibial bone defects with BMP-2 gene-modified tissue-engineered bone. Calcif Tissue Int 2005;77:55-61.

18. Lieberman JR, Daluiski A, Stevenson S, et al. The effect of regional gene therapy with bone morphogenetic protein-2-producing bone-marrow cells on the repair of segmental femoral defects in rats. J Bone Joint Surg [Am] 1999;81-A:905-17.

19. Peterson B, Zhang J, Iglesias $\mathbf{R}$, et al. Healing of critically sized femoral defects, using genetically modified mesenchymal stem cells from human adipose tissue. Tissue Eng 2005;11:120-9.

20. Lu JX, Gallur A, Flautre B, et al. Comparative study of tissue reactions to calcium phosphate ceramics among cancellous, cortical, and medullar bone sites in rabbits. J Biomed Mater Res 1998;42:357-67.

21. Lou J, Xu F, Merkel K, Manske P. Gene therapy: adenovirus-mediated human bone morphogenetic protein-2 gene transfer induces mesenchymal progenitor cell proliferation and differentiation in vitro and bone formation in vivo. J Orthop Res 1999;17:4350.

22. Shanghai Science and Technology Committee. appeal@stcsm.gov.cn (date last accessed 25 October 2006).

23. Conzemius MG, Brown TD, Zhang Y, Robinson RA. A new animal model of femoral head osteonecrosis: one that progresses to human-like mechanical failure. $J$ Orthop Res 2002;20:303-9.

24. Noshi T, Yoshikawa T, Ikeuchi $\mathbf{M}$, et al. Enhancement of the in vivo osteogenic potential of marrow/hydroxyapatite composites by bovine bone morphogenetic protein. J Biomed Mater Res 2000;52:621-30.

25. Huiskes R, Vam Rietbergen B. Biomechanics of bone. In: Mow VC, Huiskes R, eds basic orthopedic biomechanics \& mechano-biology. Philadelphia etc: Lippincott, Williams \& Wilkins, 2003:20

26. Newton B, Crawford CJ, Powers DL, Allen BL Jr. The immature goat as an animal model for Legg-Calve-Perthes disease. J Invest Surg 1994;7:417-30.

27. Mont MA, Carbone JJ, Fairbank AC. Core decompression versus nonoperative management for osteonecrosis of the hip. Clin Orthop 1996;324:169-78.

28. Rosenwasser MP, Garino JP, Kiernan HA, Michelsen CB. Long term follow up of thorough debridement and cancellous bone grafting of the femoral head for avascular necrosis. Clin Orthop 1994;306:17-27.

29. Partridge KA, Oreffo RO. Gene delivery in bone tissue engineering: progress and prospects using viral and nonviral strategies. Tissue Eng 2004;10:295-307.

30. Service RF. Tissue engineers build new bone. Science 2000;289:1498-500. 